\title{
Personal Impulsivity Mediates the Effects of Neuromodulation in Economic Intertemporal Choices: A Pilot Study
}

\author{
Barbara Colombo ${ }^{1}$, Paola lannello ${ }^{2}$, Gugliemo Puglisi ${ }^{3}$, Alessandro Antonietti ${ }^{2}$ \\ ${ }_{1}^{1}$ Department of Psychology, Neuroscience Lab, Champlain College, 163 South Willard Street, Burlington, 05401 VT, USA \\ ${ }^{2}$ Department of Psychology, Università Cattolica del Sacro Cuore, Largo Gemelli 1, 20122 Milano, Italy \\ ${ }^{3}$ Laboratory of Motor Control, Department of Medical Biotechnology and Translational Medicine, Università degli Studi di \\ Milano and Humanitas Research Hospital, IRCCS, Via Viotti, 3/5 - 20133, Milano, Italy
}

The involvement of the prefrontal cortex in intertemporal choices has been long recognized. Using neurostimulation techniques, recent studies have indicated that the left dorsolateral prefrontal cortex (DLPFC) influences performance on intertemporal choice tasks. The present pilot study is aimed to explore further the DLPFC's role in intertemporal choices by assessing the influence of individual levels of impulsivity on modulating the stimulation's effects. Thirteen subjects participated in a within-subjects experiment. During the three sessions, participants received 20 minutes of transcranial direct current stimulation (tDCS; either sham, anodal, or cathodal) and were administered the Intertemporal Choice Task. Then, they completed the Barratt Impulsivity Scale and the Dickman Impulsivity Inventory. Using a repeated-measure generalized linear model, we explored the effects of stimulation on intertemporal choice (either immediate or delayed reward) on impulsive responses, defined as quick answers. The individual level of impulsivity was included in the model as a covariate. According to the results, participants made a greater number of impulsive choices favoring immediate rewards after cathodal stimulation of the left DLPFC. Additionally, a moderating role of individual impulsivity emerged. This study provides support for the involvement of the left DLPFC in intertemporal choices. We contend that the role of individual differences should be further explored to obtain a better understanding of intertemporal choice behavior.

Key words: intertemporal choice, neuromodulation, transcranial direct current stimulation, individual differences, impulsivity, delay discounting

\section{Introduction}

Intertemporal Choices in Neuroscience Research

Intertemporal choices, that is decisions involving consequences at different points in time (for a review, see Becker, Walker, \& McCord,
2017; Berns, Laibson, \& Loewenstein, 2007; Frederick, Loewenstein, \& O'Donoghue, 2002), have been studied from various perspectives within the fields of economics, psychology, and neuroscience. Evidence from the research literature suggests that when asked to choose between an immediate and a delayed reward (and not only when economic behavior is targeted; see Eikemo \& Leknes, 2019), people

Correspondence concerning this article should be addressed to Barbara Colombo, Neuroscience Lab, Champlain College, 163 South Willard Street, Burlington, 05401 VT, USA. E-mail: bcolombo@champlain.edu ORCID https://orcid.org/0000-0002-4095-9633

Received April 17, 2019

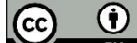


tend to undervalue the postponed reward (Lempert \& Phelps, 2016; Loewenstein \& Prelec, 1992; Myerson \& Green, 1995; Raineri \& Rachlin, 1993). The delayed reward is generally preferred when it is substantially higher than the proximal one. Choosing the second alternative depends on several factors: the length of the delay, the amount of money, and the devaluation rate of the postponed reward. This last factor, known as the temporal discounting effect, has become the principal framework used in psychology to explain how people make intertemporal choices (e.g., Benzion, Rapoport, \& Yagil, 1989; Bickel, Koffarnus, Moody, \& Wilson, 2014; Charlton et al., 2013; Green, Fristoe, \& Myerson, 1994; Story, Vlaev, Seymour, Darzi, \& Dolan, 2014). This paradigm assumes that delayed rewards are discounted more as the length of delay increases, and the rate at which delayed consequences lose value is referred to as the discount rate. Discount rates are sometimes used as a measure of impatience (Marzilli Ericson, White, Laibson, \& Cohen, 2015).

Within the field of neuroscience, functional magnetic resonance imaging (fMRI) studies have shown that several interacting neural systems are involved in the process of making intertemporal choices (McClure, Laibson, Loewenstein, \& Cohen, 2004; McClure, Marzilli Ericson, Laibson, Loewenstein, \& Cohen, 2007; Tanaka et al., 2004; Xu, Liang, Wang, Li, \& Jiang, 2009; Wittmann, Leland, \& Paulus, 2007). McClure and colleagues (2004) observed that the possibility of receiving immediate rewards instead of deferred alternatives elicits greater activation of some paralimbic structures, such as the ventral striatum, orbital frontal cortex, and medial prefrontal cortex. Frontoparietal areas, such as the dorsolateral prefrontal cortex (DLPFC), lateral orbitofrontal cortex (LOFC), and posterior parietal cortex (PPC), are activated by greater amounts of delayed rewards. These areas also play a key role in tasks requiring executive control (Miller \& Cohen, 2001; Platt \& Glimcher, 1999).

These findings support the hypothesis that the outcome of an intertemporal choice results from an interaction between two competing neural systems (De Martino, Kumran, Seymour, \& Dolan, 2006; McClure et al., 2004; Sanfey, Rilling, Aronson, Nystrom, \& Cohen, 2003; Sanfey, Loewenstein, McClure, \& Cohen, 2006). One system is linked to limbic and paralimbic responses and values immediate rewards, whereas the other one relies on frontoparietal areas and evaluates deferred gratifications. This picture is consistent with the data derived from studying both primates and human patients with lesioned DLPFC and LOFC, as they exhibited lower judgment and temporal planning skills and more frequent impulsive behaviors (Floden, Alexander, Kubu, Katz, \& Stuss, 2008; Kalenscher, 2006; Noonan et al., 2010; Wallis, 2012). It also supports the idea that the choice of immediate rewards is associated with and can be interpreted as impulsive behavior.

Neuroeconomic studies based on nonclinical samples often report an online recording of cortical activity while people are making decisions. The main limitation of this approach is that the correlational nature of the findings does not allow researchers to prove causal hypotheses regarding the actual relationships between areas and functions (Stewart \& Walsh, 2006). In recent years, neurostimulation techniques have provided a method to overcome this limitation. While brain stimulation is applied, a target area is either inhibited or activated to explore its specific influence on intertemporal choices. More specifically, transcranial direct current stimulation (tDCS) produces a continuous low-intensity electric current on the scalp to increase or decrease cortical excitability by depolarizing or hyperpolarizing, respectively, cortical neurons at a subthreshold level (Paulus, Peterchev, \& Ridding, 2013). Overall, anodal stimulation, which increases the spontaneous firing frequency of cortical neurons, has been reported to enhance the performance of cognitive tasks (Fregni et al., 2005; Javadi, Cheng, \& Walsh, 2012; Metuki, Sela, \& Lavidor, 2012; Straube, Wolk, \& Chatterjee, 2011; Wirth et al., 2011), whereas cathodal stimulation causes an inhibition of cognitive processes (Boehringeretal, 2013; Pope \& Miall, 2012; Straubeetal, 2011). There- 
fore, when a variation in choices is observed, one can presume that the stimulated area is playing a major role within the decision-making process (Stewart \& Walsh, 2006). This hypothesis has been confirmed by several studies that used brain stimulation to moderate participants' behavior during decision-making tasks entailing immediate or impulsive responses (Colombo, Balzarotti, \& Mazzuchelli, 2016; lannello, Colombo, \& Antonietti, 2014, Oldrati, Patricelli, Colombo, \& Antonietti, 2016).

A few studies have used this methodology to examine intertemporal choices. For example, Figner and colleagues (2010) showed that repetitive transcranial magnetic stimulation (rTMS) for 15 minutes at $1 \mathrm{~Hz}$ on the left PFC led to a greater frequency of preferences for immediate rewards. These data have been interpreted as being driven by a lower level of self-regulation, i.e., being unable to resist the temptation of an immediate reward. Cho and colleagues (2010) reported that the inhibition of the right DLPFC using continuous theta burst stimulation (cTBS, an rTMS protocol wherein pulses are applied in bursts of three, delivered at a frequency of $50 \mathrm{~Hz}$ and with an interburst interval of $200 \mathrm{~ms}$ ) enhanced impulsive responses. Hecht, Walsh, and Lavidor (2013) found that individuals were more likely to choose smaller immediate gains instead of a larger delayed benefit when the left DLPFC was stimulated and the right DLPFC was inhibited through tDCS, when compared to the sham stimulation. In a recent study, $\mathrm{He}$ and colleagues (2016) used anodal high-definition tDCS (HD-tDCS) to investigate the causal role of the left DLPFC in performing the intertemporal choice (ITC) task and showed that HDtDCS over the left DLPFC lowered the delaydiscounting rate $(k)$.

These results can be explained by referring to research that supports the key role of the DLPFC in guiding executive processes (for a review, see Tanji \& Hoshi, 2008). Many neurophysiological studies on both animals and humans have confirmed that the bilateral DLPFC can be viewed as the neural correlate of the central executive system (Osaka et al., 2007). This information is relevant because it has been argued that several aspects of executive functioning (for example, working memory, inhibition, and task switching) may provide the basis for successful self-regulation (Blair \& Ursache, 2011; Hofmann, Schmeichel, \& Baddeley, 2012). Following the implications derived from these studies, we can also argue that self-regulation, which involves the inhibition of impulsive tendencies (Baumeister, Bratslavsky, Muraven, \& Tice, 1998), may be responsible for the preference for greater distal (i.e., temporally delayed) rewards instead of smaller proximal (i.e., immediate) ones (Fujita \& Carnevale, 2012). This pattern provides additional support for the claim that choosing immediate rewards can be interpreted as impulsive behavior because it is associated with a lack of inhibition of impulsive behavior.

\section{Individual Differences in the Level of Impul- sivity}

Impulsivity has been considered a multifactorial construct and literature provides evidence of multiple varieties of impulsivity (Avila et al., 2004; Dickman, 1990; Evenden, 1999), these varieties being united by a suboptimal way to handle time (Kim \& Lee, 2011).

Impulsive decision-making can be viewed as a failure to appropriately consider certain types of temporal factors. Impulsivity may refer to the tendency to weigh immediate outcomes strongly and to discount the value of delayed rewards precipitously (Frederick, Loewenstein, \& O'Donoghue, 2002; Kalenscher \& Pennartz, 2008). In addition to temporal discounting, impulsivity has been also defined as a lack of inhibitory control, which implies the inability to suppress an action and thus results in a rapid and sometimes premature response (Kim \& Lee, 2011). Lack of inhibition of impulsive behavior is linked to what has historically been called "reflection impulsivity," that is, the tendency toward rapid action before sufficient information is gathered (Kagan, Rosman, Day, Albert, \& Phillips, 1964). Framing impulsivity according to this perspective leads to assessing impulsivity levels by comparing reaction 
times; individuals who are more impulsive will tend to choose an answer quickly and without thinking (Moeller, Barratt, Dougherty, Schmitz, \& Swann, 2001). If considering impulsivity as resulting from failures in successfully handling temporal factors in decision making, it implies that individuals may vary substantially in their strategies to deal with time during decision making.

Literature suggests that there are individual differences in self-control (e.g., Paschke et al., 2016) and this is consistent, indicating the appropriateness of assessing self-control as a trait. For example, Tangney, Boone, and Baumeister (2018) developed a scale to measure trait self-control based on the survey of self-control problems and failures. Thus, we can hence assume that individuals have different levels of impulsivity depending on their self-regulation skills. This inference has been also confirmed by findings of a relationship between higher impulsivity and lower self-control, which leads to addiction related behavior (Dahlen, Martin, Ragan, \& Kuhlman, 2005; Hair \& Hampson, 2006). Moreover, impulsive individuals tend to undervalue delayed rewards more heavily (Crean, de Wit, \& Richards, 2000; Hinson, Jameson, \& Whitney, 2003; lannello, Biassoni, Nelli, Zugno, \& Colombo, 2015; Wittman \& Paulus, 2008).

\section{Present Study}

Given the promising results of brain stimulation of the left DLPFC and the interesting insights gained regarding the relationship between the DLPFC and impulsivity, the present study aimed to further explore the DLPFC's role in influencing intertemporal choices and the function of individual levels of impulsivity in modulating the effects of stimulation. We aimed to a) investigate whether people with low impulsivity levels respond to tDCS differently from those with high impulsivity, b) explore the DLPFC's role in influencing intertemporal choices by using tDCS and comparing the effects of anodal and cathodal stimulations to a control (sham) condition, and c) study the specific role of individual impulsivity in modulating the tDCS effect. The data from this initial study enable a preliminary assessment of our hypotheses and procedure; however, the results should be confirmed by a larger study.

To date, within economic temporal discounting literature, impulsivity has been measured as the tendency to discount the value of delayed rewards prematurely (Frederick, Loewenstein, \& O'Donoghue, 2002; Kalenscher \& Pennartz, 2008). The present study shifts the focus to a slightly different facet of impulsivity, thus introducing in this field of research a measure of speed responses, which correspond to the (in)ability to suppress a premature response.

After reviewing the results reported in the literature, we hypothesized that the subjects would be more impulsive - less able to control their impulsive behavior - and would have faster reaction times (as discussed above) after cathodal stimulation and less impulsive after anodal stimulation, if compared to the sham condition. Given the fact that, to the best of our knowledge, no previous study has explored the moderating role of personal impulsivity in decision-making tasks, this part of the study is exploratory. However, as impulsivity is often associated with intolerance to delay and sensitivity to immediate rewards (e.g., Robbins, 2007; Whiteside \& Lynam, 2003), we can hypothesize that a higher level of individual impulsivity should enhance the effect of cathodal stimulation and decrease the effect of anodal stimulation.

\section{Method}

\section{Participants}

Thirteen participants $(6$ men and 7 women mean age $=24.3 ; S D=5.9$ ) joined the study. $A$ Power analysis aimed at assessing the achieved power (using $\mathrm{G}^{*}$ Power software), considering the sample size, the within subject design and 24 measurements for the 3 conditions returned a power $(1-\beta)$ of .97 . The power analysis calculation dealt with the main effects and was based on expected effect size of Cohen's $f=.25$. 
The participants included undergraduate and graduate students recruited through advertising on university message boards. All participants were right-handed and had no metallic implants. Individuals affected by attention deficit hyperactivity disorder (ADHD) or neuropsychiatric disorders as well as smokers, alcoholics, and people with substance abuse - all of whom usually display atypical preferences for immediate gratification (Wittman \& Paulus, 2007) - were excluded.

\section{Procedure}

The IRB of the Catholic University approved the research project. Each participant read and signed an informed consent form prior to the experiment. Information concerning the reward system for participants was included in the informed consent form.

The design procedure, a within-subjects design, consisted of sessions lasting $40 \mathrm{~min}$ utes, which occurred once a week for three consecutive weeks.

Each session had the same structure, which is as follows:

1. Twenty minutes of tDCS stimulation in three conditions and in counter-balanced sequence for each of the three sessions (i.e., sham, anodal, cathodal);

2. ITC task;

3. The third session had two additional phases:

a. Application of the impulsivity inventories;

b. Reward (one reward among the ones selected by the participants during the three section was randomly sorted and awarded to the participant)

Self-report impulsivity inventories were administered during the last session - rather than at the beginning of the entire experiment - to avoid the possibility that the participants' explicit and conscious answers about their own level of impulsivity might affect their performance on the subsequent behavioral task (functioning as a prime) by causing them to reflect on their impulsivity.

\section{Tools}

Transcranial Direct Current Stimulation. tDCS was delivered through two saline-soaked sponge electrodes $\left(25 \mathrm{~cm}^{2}\right)$ using a constantcurrent stimulator (HDC Series by Newronika S.r.I). The active electrode was placed over the F3 position of the EEG 10-20 System (corresponding to the left DLPFC), and the control electrode was placed over the right triceps muscle.

As part of the experiment, participants underwent three different stimulation conditions - anodal, cathodal, and sham - on three different days (once a week) in a counterbalanced manner. To prevent subjects from differentiating between real and sham stimulations, the current was slowly increased to $1.5 \mathrm{~mA}$ over a period of 30 seconds. For real stimulation (i.e., either cathodal or anodal), after 30 seconds, the current was maintained at $1.5 \mathrm{~mA}$ for 20 minutes, whereas during the sham stimulation, the current was slowly decreased back to zero over 30 seconds.

Intertemporal Choice Task (ITC). We used the task proposed by McClure et al. (2004). Participants were presented with a series of 24 binary choices. Each pair consisted of two alternative monetary outcomes, which differed in both specific amounts $(5-80 €)$ and times of availability (ranging from the day of the experimental session to six weeks later). Specifically, in each trial, participants had to choose between a smaller amount of money that would be immediately available and a larger amount that would be received after some time delay. The earlier rewards could be $5 €$ or $40 €$, and the latter could exceed the former by $15 \%, 25 \%$, $30 \%$, or $50 \%$. The second reward could be delayed by two, four, or six weeks.

The task was administrated using a laptop computer, and the two alternatives were presented on the two sides of the screen. Participants indicated their responses by clicking the mouse to select their chosen reward, and there was no time limit. In accordance with our definition of impulsivity as discussed in the Intro- 
duction, the response time (RT) was recorded. The lower the RT, the more impulsive the subjects.

At the end of the experiment (i.e., the conclusion of the third weekly session), participants were given a reward. One of the trials from the three sessions was randomly selected, and the participant received the reward according to the choice he or she had made in that trial. If the subject had chosen the immediate reward, the corresponding amount of money was given before he or she left the session; if the participant had chosen the delayed reward, he or she was asked to come back to the lab two, four, or six weeks later (according to the time interval specified in that delayed option) to receive the corresponding amount of money. Participants were informed about how the rewards would be assigned when they signed the informed consent form.

Barratt Impulsivity Scale. At the end of the last session, the Italian version of the 30 -item Barratt Impulsivity Scale Version 11 (BIS-11; Fossati, Di Ceglie, Acquarini, \& Barratt, 2001) was administered. Related to impulsivity, it measures six primary factors (attention, motor, self-control, cognitive complexity, perseverance, and cognitive instability) as well as three secondary factors (attentional, motor, and nonplanning). All items are rated on a 4-point scale $(1=$ rarely or never; 2 = occasionally; $3=$ often; $4=$ almost always or always). The BIS-11 has demonstrated an acceptable level of internal consistency (Cronbach's alpha $=.79$ ). We computed scores for each of the three subscales assessing secondary factors (attentional impulsivity: Cronbach's alpha $=.73$; motor impulsivity: Cronbach's alpha $=.78$; nonplanning impulsivity: Cronbach's alpha $=.70$ ).

Dickman Impulsivity Inventory. Individual impulsivity was also assessed by using the short version of the Dickman Impulsivity Inventory (DII-S; Claes, Vertommen, \& Braspenning, 2000; Dickman, 1990). We translated the original scale into Italian using a standardized procedure including two independent translations, followed by determination of a consensus translation by an expert panel. The translated scale demonstrated good internal con- sistency in the present study (Cronbach's alpha $=.75$ ). This inventory was designed to assess the personality trait of impulsiveness by using 23 true-false items organized into two subscales: functional impulsivity (the tendency to act with relatively little forethought when doing so is optimal; Cronbach's alpha $=.70$ ) and dysfunctional impulsivity (the tendency to act with relatively little forethought when doing so causes problems; Cronbach's alpha $=.71$ ).

\section{Results}

\section{Statistical Analyses}

All statistical analyses were performed using IBM SPSS software (IBM, Armonk, NY, USA, version 20). The level of significance was set at $\alpha=0.05$. We used the Kolmogorov-Smirnov test to check for the normal distribution of data. A repeated-measures generalized linear model (GLM) was used to explore the withinsubjects effects of the type of stimulation on the different dependent variables (see below). Follow-up regressions were used to explore the specific role of individual differences.

\section{Main Effect of Stimulation}

We first tested for possible gender differences. As no significant difference emerged within our sample, we did not add gender as a betweensubjects variable in the subsequent analyses. We then ran a repeated measures ANOVA aimed at exploring possible differences among tDCS conditions depending on the type of reward (immediate vs. postponed): results (non significant but coherent with previous literature findings) are reported in the supplementary materials.

Because we were interested in exploring different impulsive behaviors, as reflected by RTs, we used a repeated-measures GLM to explore the effects of the type of stimulation (independent within-subjects variable) and the kind of reward chosen (immediate versus postponed reward) on the RT (faster responses were considered as more impulsive) for the different choices (small or big reward - we 
retained this distinction when looking at RTs because we were interested in exploring the differences in behavior depending on the choice). All the BIS-11 and DII-S main subscales were included in the model as covariates.

No main effects of the stimulation $\left(F_{2 ; 14}=\right.$ $1.243 ; p=.27 ; \eta^{2}=.17$ ) or the type of reward
$\left(F_{1 ; 7}=1.66 ; p=.24 ; \eta^{2}=.19\right)$ on RT emerged. However, the results highlighted an interaction effect of the stimulation, the kind of reward, and functional impulsivity: $F_{2 ; 6}=8.27 ; p<.05$; $\eta^{2}=.73$. An interaction effect among stimulation, kind of reward, and attentional impulsivity emerged: $F_{2 ; 6}=10.95 ; p<.01 ; \eta^{2}=.78$. A third interaction effect among stimulation, kind of

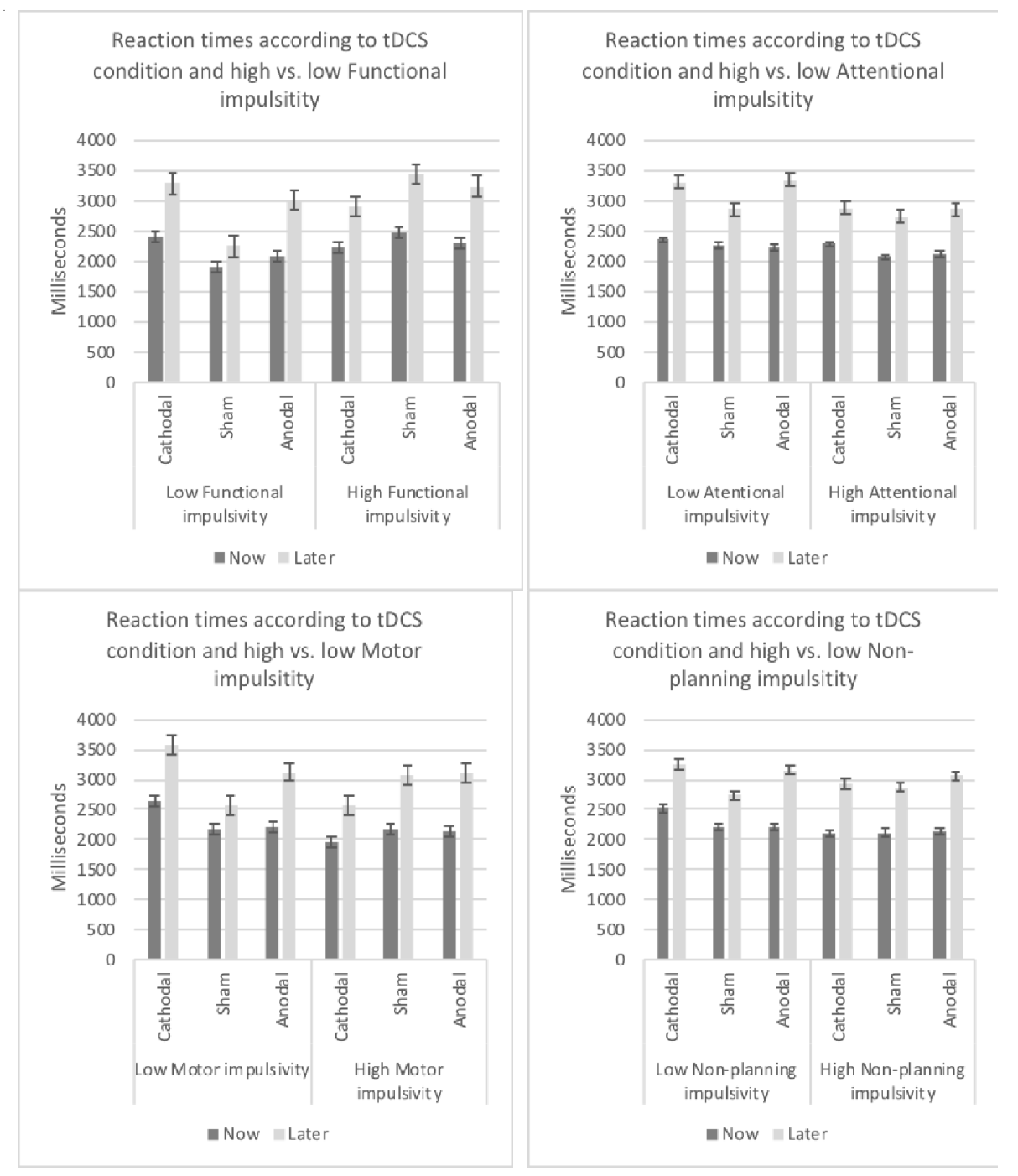

Figure 1 Response Time depending on tDCS condition, the type of reward and level of impulsivity. Errors bars show Standard Errors. 
Table 1 Follow-up regressions using impulsive responses as the criterion

\begin{tabular}{|c|c|c|c|c|}
\hline Predictors & & $b$ & $S E b$ & $\beta$ \\
\hline \multicolumn{5}{|l|}{ BIS - Motor Impulsivity } \\
\hline \multirow[t]{3}{*}{ Anodal Immediate Reward } & Constant & 1.14 & 8.08 & \\
\hline & $\mathrm{BIS} \mathrm{MI}$ & .72 & .42 & .46 \\
\hline & & & & \\
\hline \multirow[t]{3}{*}{ Anodal Postponed Reward } & Constant & -.13 .34 & 9.13 & \\
\hline & $\mathrm{BIS} \mathrm{MI}$ & 1.28 & .47 & $.64^{*}$ \\
\hline & & & & \\
\hline \multirow[t]{3}{*}{ Sham Immediate Reward } & Constant & -3.68 & 8.27 & \\
\hline & $\mathrm{BIS} \mathrm{MI}$ & .89 & .46 & .50 \\
\hline & & & & \\
\hline \multirow[t]{3}{*}{ Sham Postponed Reward } & Constant & -8.15 & 10.72 & \\
\hline & $\mathrm{BIS} \mathrm{MI}$ & .99 & .55 & .48 \\
\hline & & & & \\
\hline \multirow[t]{3}{*}{ Cathodal Immediate Reward } & Constant & -.82 & 7.45 & \\
\hline & $\mathrm{BIS} \mathrm{MI}$ & .86 & .49 & $.54^{*}$ \\
\hline & & & & \\
\hline \multirow[t]{3}{*}{ Cathodal Postponed Reward } & Constant & -12.94 & 9.09 & \\
\hline & BIS MI & 1.31 & .47 & $.65^{*}$ \\
\hline & & & & \\
\hline \multicolumn{5}{|l|}{ DII - Functional Impulsivity } \\
\hline & & $b$ & SEb & $\beta$ \\
\hline \multirow[t]{3}{*}{ Anodal Immediate Reward } & Constant & 6.79 & 4.44 & \\
\hline & $\mathrm{DII}-\mathrm{FI}$ & 1.96 & 1.01 & .51 \\
\hline & & & & \\
\hline \multirow[t]{3}{*}{ Anodal Postponed Reward } & Constant & -1.53 & 5.29 & \\
\hline & $\mathrm{DII}-\mathrm{FI}$ & 3.05 & 1.20 & $.61^{*}$ \\
\hline & & & & \\
\hline \multirow[t]{3}{*}{ Sham Immediate Reward } & Constant & 5.52 & 5.29 & \\
\hline & DII - FI & 1.89 & 1.20 & .43 \\
\hline & & & & \\
\hline \multirow[t]{3}{*}{ Sham Postponed Reward } & Constant & -2.35 & 5.44 & \\
\hline & DIl - FI & 3.18 & 1.23 & $.61^{*}$ \\
\hline & & & & \\
\hline \multirow[t]{3}{*}{ Cathodal Immediate Reward } & Constant & 6.51 & 4.37 & \\
\hline & DII - FI & 2.21 & .99 & $.56^{*}$ \\
\hline & & & & \\
\hline \multirow[t]{3}{*}{ Cathodal Postponed Reward } & Constant & .07 & 5.51 & \\
\hline & $\mathrm{DII}-\mathrm{FI}$ & 2.89 & 1.25 & $.57^{\star}$ \\
\hline & & & & \\
\hline
\end{tabular}

Note. $b$ represents unstandardized regression weights, SE $b$ corresponds to the standard error for the unstandardized regression weights, $\beta$ indicates the standardized regression weights.

* indicates $p<.05$ 
reward, and motor impulsivity was observed: $F_{2 ; 6}=5.66 ; p<.05 ; \eta^{2}=.65$. Finally, an interaction effect among stimulation, kind of reward, and non-planning impulsivity emerged: $F_{2 ; 6}=$ 7.07; $p<.05 ; \eta^{2}=.70$.

Postponed rewards tended to elicit more impulsive (faster) answers. Whereas anodal stimulation appeared to have levelled the difference between immediate vs. postponed rewards, after cathodal stimulation individuals reported faster responses when presented with postponed rewards, and the extent of these differences varied depending on the type of impulsivity (see Figure 1).

A follow-up regression (Table 1) to explore the specific role of functional impulsivity in modulating impulsive responses highlighted a significant effect after the anodal stimulation when the reward was delayed $(b=3.05$; SEb $=1.20$; $\mathrm{b}=.61 ; p<.05)$. The same effect emerged in the sham condition for delayed rewards $(b=3.18$; $S E b=1.23 ; b=.61 ; p<.05)$. After the cathodal stimulation, functional impulsivity appeared to modulate impulsive answers both when the reward was immediate $(b=2.21 ; S E b=.99 ; b=$ $.56 ; p<.05)$ and when it was postponed $(b=$ 2.90; $S E b=1.25 ; b=.57 ; p<.05)$.

To better understand the role of attentional impulsivity in modulating impulsive responses, we ran a follow-up regression. No significant effect emerged.

A follow-up regression to explore the specific role of motor impulsivity in moderating impulsive responses showed a significant effect after anodal stimulation when the reward was delayed $(b=1.28 ;$ SE $b=.47 ; b=.64 ; p<.01)$. After cathodal stimulation, motor impulsivity appeared to moderate impulsive answers both when the reward was immediate $(b=.86$; $S E b=.40 ; b=.54 ; p=.05)$ and when it was postponed $(b=1.31 ; S E b=.47 ; b=.65 ; p<.01)$. No effect emerged under the sham condition.

A follow-up regression focusing on non-planning impulsivity found no significant effect.

\section{Discussion}

The within-subjects pilot study presented in this paper explored the effect of tDCS on the left DLPFC in moderating impulsive intertemporal choice by considering a possible moderating effect of individual levels of impulsivity.

Findings previously reported in the literature (Hecht, Walsh, \& Lavidor, 2013) indicated that a greater number of choices favoring immediate rewards occurred after cathodal stimulation of the left DLPFC. Our results are in line with these findings, even if we focused on a different facet of impulsivity, as measured through response speed (reaction time). Specifically, even if a main effect of the stimulation did not emerge - possibly because of our small sample size - we noted the participants tendency to report more impulsive (faster) responses after cathodal stimulation when presented with immediate rewards.

Our study added a further level of complexity by including the role of individual impulsivity in the model. We found significant interaction effects, thereby supporting the notion of a moderating role played by individual differences in impulsivity. Especially, we found that motor impulsivity (the tendency to act without thinking) and functional impulsivity (the tendency to act with little forethought in situations where such behavior is beneficial) moderated the effect of cathodal stimulation (by way of increasing its effect), both when the reward was immediate and when it was postponed. The same two types of impulsivity also moderated the effect of anodal stimulation (again increasing the effect of stimulation), but only for delayed rewards. These data suggest that when the DLPFC is inhibited, people become more impulsive, favor immediate rewards, and make faster and less mediated decisions; moreover, this effect is enhanced for individuals who already tend to act without thinking.

By contrast, when the activity of the DLPFC was enhanced, people tended to ponder their decision longer and chose delayed rewards more often. The fact that being more impulsive increased the effect of anodal stimulation for delayed rewards implies that people, who are more impulsive, tend to change their behavior significantly and become more reflective after anodal stimulation but only in case of delayed rewards. In other words, the tendency 
to delay discounting per se is not affected, but if an impulsive person considers the delayed rewards, then he or she is more likely to give more thought to the decision and eventually choose the delayed reward option after anodal stimulation. These results confirm previous findings suggesting that impulsive people tend to have an altered sense of time (Wittman \& Paulus, 2007), implying that they opt for smaller and immediate rewards because they overestimate the duration of time intervals. This finding explains these individuals' tendency to discount the value of delayed rewards and prefer immediate benefits. In short, time seems to take longer for them and is thus perceived as a higher cost, leading them to choose the immediate reward. The fact that after anodal stimulation people are more likely to choose the delayed rewards and spend a longer time making their decision could be explained as a possible effect of the anodal stimulation, which leads individuals to consider more carefully the exact weight of time when evaluating the value of the rewards.

An additional consideration related to these results, which should be addressed further in future studies, concerns the age of our subjects. Steinberg and colleagues (2009) reported that teenagers tend to be less oriented toward the future and prefer to focus on the immediate present. This perspective would lead to a stronger preference for immediate rewards, regardless of any other consideration. Although our participants were older than teenagers, the mean age of 24 could justify the possibility that a stronger-than-average cognitive focus on the present might still play a role in their reasoning strategies.

Interestingly enough, no effect of individual levels of impulsivity was found when we considered impulsive responses under the sham condition. This result partially contradicts previous findings indicating that personal impulsivity was associated with a preference for proximal reward in temporal discounting tasks (Kirby \& Hernstein, 1995; Pine, Shiner, Seymour \& Dolan, 2010). One possible explanation could lie in the nature of self-report scales, which assess what individuals believe about their own behavior. Specifically, individuals' beliefs about their tendency to behave in certain ways have been formed through numerous experiences over time. When participants are asked to complete a questionnaire about their level of impulsivity, they refer to these consolidated and established beliefs about their own impulsivity. Apparently, the manner in which individuals tended to rate their own behavior was affected by the stimulation, leading them to be more focused on actual behavioral performance beyond the immediate taskrelated experience, whereas the same pattern did not arise in the sham condition. This is an interesting discovery that should be explored in depth in future studies.

Another possible explanation of this conflict between our results and previous findings could be due to the different scales used to assess impulsivity. We used fine scales that were probably able to discriminate quite extensively among different kinds of impulsivity, thus providing more sophisticated results. This fact highlights an interesting interaction effect that should be investigated in depth in future studies. Overall, our data suggest that the effect of brain stimulation alone cannot explain individuals' behavior; rather, we must consider individual differences as well to acquire a better understanding of the complicated mechanisms underlying intertemporal choices.

\section{Limitations}

The present study, which constitutes a first promising step toward understanding the role of individual differences in modulating the effect of brain stimulation on specific cognitive tasks, has some limitations that should be addressed in future studies. First, the small sample size of the pilot study represents an obvious limitation and may limit the generalizability of the results. This study, however, should be considered an initial exploratory inquiry; we recognize that replication with a larger sample would be needed to further corroborate these preliminary, though encouraging, findings. Replication should also occur with 
different age cohorts to examine the possible effect of age.

A second limitation concerns the exclusive reliance on self-reported rating scales to measure individual impulsivity. Although literature on individual differences has relied mainly on self-reported measures, integrating other types of measures (such as direct observations or behavioral measures) could provide a more comprehensive and multifaceted picture of the construct. Future research could address this issue by combining different methods of measuring individual impulsivity.

\section{Conclusion}

The findings of the present study, although they will have to be confirmed in follow-up studies, offer several interesting implications. Low behavioral inhibition and high reward sensitivity are generally considered major predictors of risk-taking behavior (Gullo \& Dawe, 2008). Conversely, there is a positive correlation between the ability to resist impulsive reactions and the achievement of positive life outcomes (Keough et al., 1999). Taken together, these findings suggest that delay-discounting behavior is influenced by brain stimulation, but not in a direct and deterministic manner. What seems crucial is the interaction between stimulation and individuals' impulsivity levels, which indicates that behavior is affected by different factors that pertain to distinct domains. Our data, by highlighting how the tDCS affected behavior differently depending on the individual level of impulsivity, suggest an important role of individual impulsivity that should be further explored to better understand the effect of tDCS itself. Our results suggest that a tDCS-based protocol could potentially be used both in research activity and as a form of support for populations prone to risk-taking behavior. However, the protocol and the expected outcomes should be calibrated according to individual levels of impulsivity. This recommendation is in line with a growing body of research within the tDCS literature that emphasizes considering individual differences, such as gender, physiological differences, and cognitive abili- ties (Jones \& Berryhill, 2012; Krause \& Kadosh, 2014), to thoroughly understand the differential effects of stimulation on participants.

\section{References}

Avila, C., Cuenca, I., Felix, V., Parcet, M., \& Miranda, A. (2004). Measuring impulsivity in school-aged boys and examining its relationship with ADHD and ODD ratings. Journal of Abnormal Child Psychology, 32(3), 295-304.

Baumeister, R. F., Bratslavsky, E., Muraven, M., \& Tice, D. M. (1998). Ego depletion: Is the active self a limited resource?. Journal of Personality and Social Psychology, 74(5), 1252-1265. https:// doi.org/10.1037/0022-3514.74.5.1252

Baumeister, R. F., Heatherton, T. F., \& Tice, D. M. (1994). Losing control: How and why people fail at self-regulation. San Diego, CA, US: Academic Press.

Becker, C., Walker, D., \& McCord, C. (2017). A systematic literature review on intertemporal choice in software engineering-protocol and results. arXiv preprint arXiv:1701.08310.

Berns, G. S., Laibson, D., \& Loewenstein, G. (2007). Intertemporal choice - toward an integrative framework. Trends in Cognitive Science, 11(11), 482-488. https://doi.org/10.1016/j.tics.2007.08.011

Bickel, W. K., Koffarnus, M. N., Moody, L., \& Wilson, A. G. (2014). The behavioral-and neuro-economic process of temporal discounting: A candidate behavioral marker of addiction. Neuropharmacology, 76, 518-527. https://doi.org/10.1016/ j.neuropharm.2013.06.013

Benzion, U., Rapoport, A., \& Yagil, J. (1989). Discount rates inferred from decisions: An experimental study. Management Science, 35(3), 270284

Blair, C., \& Ursache, A. (2011). A bidirectional model of executive functions and self-regulation. Handbook of self-regulation: Research, theory, and applications, 2, 300-320.

Boehringer, A., Macher, K., Dukart, J., Villringer, A., \& Pleger, B. (2013). Cerebellar transcranial direct current stimulation modulates verbal working memory. Brain Stimulation, 6(4), 649-653. https:/ /doi.org/10.1016/j.brs.2012.10.001

Chabris, C. F., Laibson, D. I., \& Schuldt, J. P. (2010). Intertemporal choice. In S. N. Durlauf \& L. E. Blume (Eds.), Behavioural and Experimental Economics (pp. 168-177). The New Palgrave Economics Collection. Palgrave Macmillan, London .

Calkins, S. D., \& Fox, N. A. (2002). Self-regulatory processes in early personality development: A 
multilevel approach to the study of childhood social withdrawal and aggression. Development and Psychopathology, 14(3), 477-498. doi: https:// doi.org/10.1017/S095457940200305X

Charlton, S. R., Yi, R., Porter, C., Carter, A. E., Bickel, W., \& Rachlin, H. (2013). Now for me, later for us? Effects of group context on temporal discounting. Journal of Behavioral Decision Making, 26(2), 118-127.https://doi.org/10.1002/ bdm.766

Cho, S. S., Ko, J. H., Pellecchia, G., Van Eimeren, T. Cilia, R., \& Strafella, A. P. (2010). Continuous theta burst stimulation of right dorsolateral prefrontal cortex induces changes in impulsivity level. Brain Stimulation, 3(3), 170-176. https://doi.org/10.1016/ j.brs.2009.10.002

Claes, L., Vertommen, H., \& Braspenning, N. (2000). Psychometric properties of the Dickman Impulsivity Inventory. Personality and Individual Differences, 29(1), 27-35. https://doi.org/10.1016/ S0191-8869(99)00172-5

Colombo, B., Balzarotti, S., \& Mazzucchelli, N. (2016) The influence of the dorsolateral prefrontal cortex on attentional behavior and decision making. A t-DCS study on emotionally vs. functionally designed objects. Brain and Cognition, 104, 7-14 https://doi.org/10.1016/j.bandc.2016.01.007

Crean, J. P., de Wit, H., \& Richards, J. B. (2000). Reward discounting as a measure of behavior in a psychiatric outpatient population. Experimental and Clinical Psychopharmacology, 8(2), 155-162. http://dx.doi.org/10.1037/1064-1297.8.2.155

Dahlen, E. R., Martin, R. C., Ragan, K., \& Kuhlman, M M. (2005). Driving anger, sensation seeking, impulsiveness, and boredom proneness in the prediction of unsafe driving. Accident Analysis \& Prevention, 37(2), 341-348. https://doi.org/10.1016/ j.aap.2004.10.006

De Martino, B., Kumaran, D., Seymour, B., \& Dolan, R. J. (2006). Frames, biases, and rational decision-making in the human brain. Science, 313(5787), 684-687. https://doi.org/10.1126/science. 1128356

Dickman, S. J. (1990). Functional and dysfunctional impulsivity: Personality and cognitive correlates. Journal of Personality and Social Psychology, 58(1), 95-10. http://dx.doi.org/10.1037/00223514.58.1.95

Evenden, J. L. (1999). Varieties of impulsivity. Psychopharmacology, 146, 348-361.

Marzilli Ericson, K. M., White, J. M., Laibson, D., \& Cohen, J. D. (2015). Money earlier or later? Simple heuristics explain intertemporal choices better than delay discounting does. Psychological Sci- ence, 26(6), 826-833. https://doi.org/10.1177/ 0956797615572232

Figner, B., Knoch, D., Johnson, E. J., Krosch, A. R. Lisanby, S. H., Fehr, E., \& Weber, E. U. (2010). Lateral prefrontal cortex and self-control in intertemporal choice. Nature Neuroscience, 13(5), 538-539.

Floden, D., Alexander, M. P., Kubu, C. S., Katz, D., \& Stuss, D. T. (2008). Impulsivity and risk-taking behavior in focal frontal lobe lesions. Neuropsychologia, 46(1), 213-223. https://doi.org/ 10.1016/j.neuropsychologia.2007.07.020

Fossati, A., Di Ceglie, A., Acquarini, E., \& Barratt, E. S. (2001). Psychometric properties of an Italian version of the Barratt Impulsiveness Scale-11 (BIS11) in nonclinical subjects. Journal of Clinical Psychology, 57(6), 815-828. https://doi.org/ 10.1002/jclp. 1051

Frederick, S., Loewenstein, G., \& O'Donoghue, T. (2002). Time discounting and time preference: A critical review. Journal of Economic Literature, 40(2), 351-401. doi: 10.1257/ 002205102320161311

Fregni, F., Boggio, P. S., Nitsche, M., Bermpohl, F., Antal, A., Feredoes, E., Marcoli, M. A., Rigonatti, S. P., Silva, M. T., Paulus, W., \& Pascual-Leone, A. (2005). Anodal transcranial direct current stimulation of prefrontal cortex enhances working memory. Experimental Brain Research, 166(1), 23-30. https://doi.org/10.1007/s00221-005-2334-

Fujita, K., \& Carnevale, J. J. (2012). Transcending temptation through abstraction: The role of construal level in self-control. Current Directions in Psychological Science, 21(4), 248-252. https:/ /doi.org/10.1177/0963721412449169

Green, L., Fristoe, N., \& Myerson, J. (1994). Temporal discounting and preference reversals in choice between delayed outcomes. Psychonomic Bulletin \& Review, 1(3), 383-389. https://doi.org/ 10.3758/BF03213979

Green, L., \& Myerson, J. (2004). A discounting framework for choice with delayed and probabilistic rewards. Psychological Bulletin, 130(5), 769792. http://dx.doi.org/10.1037/0033-2909.130. 5.769

Green, L., Myerson, J., \& Ostaszewski, P. (1999). Discounting of delayed rewards across the life span: Age differences in individual discounting functions. Behavioural Processes, 46(1), 89-96. https://doi.org/10.1016/S0376-6357(99)00021-2

Gullo, M. J., \& Dawe, S. (2008). Impulsivity and adolescent substance use: Rashly dismissed as "allbad"?. Neuroscience \& Biobehavioral Re- 
views, 32(8), 1507-1518. https://doi.org/10.1016/ j.neubiorev.2008.06.003

Hair, P., \& Hampson, S. E. (2006). The role of impulsivity in predicting maladaptive behaviour among female students. Personality and Individual Differences, 40(5), 943-952. https://doi.org/10.1016/ j.paid.2005.10.002

He, Q., Chen, M., Chen, C., Xue, G., Feng, T., \& Bechara, A. (2016). Anodal stimulation of the left DLPFC increases IGT scores and decreases delay discounting rate in healthy males. Frontiers in Psychology, 7, 1421. https://doi.org/10.3389/ fpsyg.2016.01421

Hecht, D., Walsh, V., \& Lavidor, M. (2013). Bi-frontal direct current stimulation affects delay discounting choices. Cognitive Neuroscience, 4(1), 7-11. https://doi.org/10.1080/17588928.2011.638139

Hinson, J. M., Jameson, T. L., \& Whitney, P. (2003). Impulsive decision making and working memory. Journal of Experimental Psychology: Learning, Memory, and Cognition, 29(2), 298-306. http:// dx.doi.org/10.1037/0278-7393.29.2.298

Hofmann, W., Schmeichel, B. J., \& Baddeley, A. D. (2012). Executive functions and self-regulation. Trends in Cognitive Science, 16(3), 174-180. https://doi.org/10.1016/j.tics.2012.01.006

lannello, P., Biassoni, F., Nelli, B., Zugno, E., \& Colombo, B. (2015). The influence of menstrual cycle and impulsivity on risk-taking behaviour. Neuropsychological Trends, 17, 47-52. https://doi.org/ 10.7358/neur-2015-017-iann

lannello, P., Colombo, B., \& Antonietti, A. (2014). Noninvasive brain stimulation techniques in the study of intuition. Handbook of Research Methods on Intuition. Cheltenham: Edward Elgar.

Javadi, A. H., Cheng, P., \& Walsh, V. (2012). Short duration transcranial direct current stimulation (tDCS) modulates verbal memory. Brain Stimulation, 5(4), 468-474. https://doi.org/10.1016/ j.brs.2011.08.003

Jones, K. T., \& Berryhill, M. E. (2012). Parietal contributions to visual working memory depend on task difficulty. Frontiers in Psychiatry, 10 September. https://doi.org/10.3389/fpsyt.2012.00081

Kagan, J., Rosman, B. L., Day, D., Albert, J., \& Phillips, W. (1964). Information processing in the child: Significance of analytic and reflective attitudes. Psychological Monographs, 78(1), 1-37. http:// dx.doi.org/10.1037/h0093830

Kalenscher, T., Ohmann, T., \& Güntürkün, O. (2006). The neuroscience of impulsive and self-controlled decisions. International Journal of Psychophysiology, 62(2), 203-211. https://doi.org/10.1016/ j.ijpsycho.2006.05.010
Kalenscher, T., \& Pennartz, C. M. A. (2008). Is a bird in the hand worth two in the future? The neuroeconomics of intertemporal decision-making. Progress in Neurobiology, 84, 284-315.

Keough, K. A., Zimbardo, P. G., \& Boyd, J. N. (1999). Who's smoking, drinking, and using drugs? Time perspective as a predictor of substance use. $\mathrm{Ba}$ sic and Applied Social Psychology, 21(2), 149168. https://doi.org/10.1207/S15324834BA210207

Kim, S., \& Lee, D. (2011). Prefrontal cortex and impulsive decision making. Biological Psychiatry, 69, 1140-1146.

Kirby, K. N., \& Herrnstein, R. J. (1995). Preference reversals due to myopic discounting of delayed reward. Psychological Science, 6(2), 83-89. https://doi.org/10.1111/j.1467-9280.1995.tb00311.x

Krause, B., \& Cohen Kadosh, R. (2014). Not all brains are created equal: The relevance of individual differences in responsiveness to transcranial electrical stimulation. Frontiers in Systems Neuroscience, 24 February. https://doi.org/10.3389/ fnsys.2014.00025

Lempert, K. M., \& Phelps, E. A. (2016). The malleability of intertemporal choice. Trends in Cognitive Science, 20(1), 64-74. https://doi.org/10.1016/ j.tics.2015.09.005

Loewenstein, G., \& Prelec, D. (1992). Anomalies in intertemporal choice: Evidence and an interpretation. The Quarterly Journal of Economics, 107(2), 573-597. https://doi.org/10.2307/ 2118482

Marzilli Ericson, K. M., White, J. M., Laibson, D., \& Cohen, J. D. (2015). Money earlier or later? Simple heuristics explain intertemporal choices better than delay discounting does. Psychological Science, 26(6), 826-833. https://doi.org/10.1177/ 0956797615572232

McClure, S. M., Laibson, D. I., Loewenstein, G., \& Cohen, J. D. (2004). Separate neural systems value immediate and delayed monetary rewards. Science, 306(5695), 503-507. https:// doi.org/10.1126/science. 1100907

McClure, S. M., Marzilli Ericson, K. M., Laibson, D. I., Loewenstein, G., \& Cohen, J. D. (2007). Time discounting for primary rewards. Journal of Neuroscience, 27(21), 5796-5804. https://doi.org/ 10.1523/JNEUROSCI.4246-06.2007

Metuki, N., Sela, T., \& Lavidor, M. (2012). Enhancing cognitive control components of insight problems solving by anodal tDCS of the left dorsolateral prefrontal cortex. Brain Stimulation, 5(2), 110-115. https://doi.org/10.1016/j.brs.2012.03.002

Miller, E. K., \& Cohen, J. D. (2001). An integrative theory of prefrontal cortex function. Annual Re- 
view of Neuroscience, 24(1), 167-202. https:// doi.org/10.1146/annurev.neuro.24.1.167

Moeller, F. G., Barratt, E. S., Dougherty, D. M., Schmitz, J. M., \& Swann, A. C. (2001). Psychiatric aspects of impulsivity. American Journal of Psychiatry, 158(11), 1783-1793. https://doi.org/10.1176/ appi.ajp.158.11.1783

Myerson, J., \& Green, L. (1995). Discounting of delayed rewards: Models of individual choice. Journal of the Experimental Analysis of Behavior, 64(3), 263-276. https://doi.org/10.1901/ jeab.1995.64-263

Noonan, M. P., Walton, M. E., Behrens, T. E. J., Sallet, J., Buckley, M. J., \& Rushworth, M. F. S. (2010). Separate value comparison and learning mechanisms in macaque medial and lateral orbitofrontal cortex. Proceedings of the National Academy of Sciences, 107(47) 20547-20552. https://doi.org/ 10.1073/pnas.1012246107

Oldrati, V., Patricelli, J., Colombo, B., \& Antonietti, A. (2016). The role of dorsolateral prefrontal cortex in inhibition mechanism: A study on cognitive reflection test and similar tasks through neuromodulation. Neuropsychologia, 91, 499-508. https://doi.org/10.1016/j.neuropsychologia.2016. 09.010

Osaka, N., Otsuka, Y., Hirose, N., Ikeda, T., Mima, T. Fukuyama, H., \& Osaka, M. (2007). Transcranial magnetic stimulation (TMS) applied to left dorsolateral prefrontal cortex disrupts verbal working memory performance in humans. Neuroscience Letters, 418(3), 232-235. https://doi.org/10.1016/ j.neulet.2007.01.087

Paschke, L. M., Dörfel, D., Steimke, R., Trempler, I., Magrabi, A., Ludwig, V. U., Torsten, S., Stelzel, C. \& Walter, H. (2016). Individual differences in selfreported self-control predict successful emotion regulation. Social Cognitive and Affective Neuroscience, 11(8), 1193-1204. https://doi.org/10. 1093/scan/nsw036

Paulus, W., Peterchev, A. V., \& Ridding, M. (2013). Transcranial electric and magnetic stimulation: Technique and paradigms. In Handbook of clinical neurology (Vol. 116, pp. 329-342). Elsevier. https://doi.org/10.1016/B978-0-444-534972.00027-9

Pine, A., Shiner, T., Seymour, B., \& Dolan, R. J. (2010). Dopamine, time, and impulsivity in humans. Journal of Neuroscience, 30(26), 8888-8896. https:// doi.org/10.1523/JNEUROSCI.6028-09.2010

Platt, M. L., \& Glimcher, P. W. (1999). Neural correlates of decision variables in parietal cortex. $\mathrm{Na}$ ture, 400(6741), 233-238. https://doi.org/10.1038/ 22268
Pope, P. A., \& Miall, R. C. (2012). Task-specific facilitation of cognition by cathodal transcranial direct current stimulation of the cerebellum. Brain Stimulation, 5(2), 84-94. https://doi.org/10.1016/ j.brs.2012.03.006

Raineri, A., \& Rachlin, H. (1993). The effect of temporal constraints on the value of money and other commodities. Journal of Behavioral Decision Making, 6(2), 77-94. https://doi.org/10.1002/bdm 3960060202

Robbins, T. W. (2007). Shifting and stopping: Frontostriatal substrates, neurochemical modulation and clinical implications. Philosophical Transactions of the Royal Society of London, 362(1481), 917-932. https://doi.org/10.1098/rstb.2007.2097

Sanfey, A. G., Rilling, J. K., Aronson, J. A., Nystrom, L. E., \& Cohen, J. D. (2003). The neural basis of economic decision-making in the ultimatum game. Science, 300(5626), 1755-1758. https:// doi.org/10.1126/science.1082976

Sanfey, A. G., Loewenstein, G., McClure, S. M., \& Cohen, J. D. (2006). Neuroeconomics: Cross-currents in research on decision-making. Trends in Cognitive Science, 10(3), 108-116. https://doi.org/ 10.1016/j.tics.2006.01.009

Steinberg, L., Graham, S., O'Brien, L., Woolard, J., Cauffman, E., \& Banich, M. (2009). Age differences in future orientation and delay discounting. Child Development, 80(1), 28-44. https://doi.org/ 10.1111/j.1467-8624.2008.01244.x

Stewart, L., \& Walsh, V. (2006). Transcranial magnetic stimulation in human cognition. In C. Senior, T. Russelland, \& M. S. Gazzaniga (Eds.), Methods in mind (pp. 1-26). Cambridge, MA and London: MIT Press.

Story, G., Vlaev, I., Seymour, B., Darzi, A., \& Dolan, R. (2014). Does temporal discounting explain unhealthy behavior? A systematic review and reinforcement learning perspective. Frontiers in Behavioral Neuroscience, 8, 76. https://doi.org/ 10.3389/fnbeh.2014.00076

Straube, B., Wolk, D., \& Chatterjee, A. (2011). The role of the right parietal lobe in the perception of causality: A tDCS study. Experimental Brain Research, 215(3-4), 315-325. https://doi.org/10. 1007/s00221-011-2899-1

Tanaka, S. C., Doya, K., Okada, G., Ueda, K., Okamoto, Y., \& Yamawaki, S. (2004). Prediction of immediate and future rewards differentially recruits cortico-basal ganglia loops. Nature Neuroscience, 7(8), 887-893. https://doi.org/10.1038/ nn1279

Tangney, J. P., Boone, A. L., \& Baumeister, R. F (2018). High self-control predicts good adjustment, 
less pathology, better grades, and interpersonal success. Journal of Personality, 72(2) 271-324. https://doi.org/10.1111/j.0022-3506.2004.00263.x

Tanji, J., \& Hoshi, E. (2008). Role of the lateral prefrontal cortex in executive behavioral control. Physiological Review, 88(1), 37-57. https://doi.org/ 10.1152/physrev.00014.2007

Xu, L., Liang, Z. Y., Wang, K., Li, S., \& Jiang, T. (2009). Neural mechanism of intertemporal choice: From discounting future gains to future losses. Brain Research, 1261, 65-74. https://doi.org/ 10.1016/j.brainres.2008.12.061

Whiteside, S. P., \& Lynam, D. R. (2003). Understanding the role of impulsivity and externalizing psychopathology in alcohol abuse: Application of the UPPS Impulsive Behavior Scale. Experimental and Clinical Psychopharmacology, 11(3), 210. https:/ /doi.org/10.1037/1064-1297.11.3.210

Wallis, J. D. (2012). Cross-species studies of orbitofrontal cortex and value-based decision- making. Nature Neuroscience, 15(1), 13-19. https://doi.org/10.1038/nn.2956

Wirth, M., Rahman, R. A., Kuenecke, J., Koenig, T., Horn, H., Sommer, W., \& Dierks, T. (2011). Effects of transcranial direct current stimulation (tDCS) on behaviour and electrophysiology of language production. Neuropsychologia, 49(14), 39893998. https://doi.org/10.1016/j.neuropsychologia. 2011.10.015

Wittmann, M., \& Paulus, M. P. (2008). Decision making, impulsivity and time perception. Trends in Cognitive Science, 12(1), 7-12. https://doi.org/ 10.1016/j.tics.2007.10.004

Wittmann, M., Leland, D. S., \& Paulus, M. P. (2007) Time and decision making: Differential contribution of the posterior insular cortex and the striatum during a delay discounting task. Experimental Brain Research, 179(4), 643-653. https://doi.org/ 10.1007/s00221-006-0822-y

\section{Appendix}

We ran a repeated measures ANOVA aimed at exploring possible differences among tDCS conditions depending on the type of reward (immediate vs. postponed). No effect of the tDCS condition emerged $\left(F_{2 ; 24}=2.41 ; p=.11\right)$. This could be due to our small sample size. If we consider the trend of answers, people tended to choose the immediate reward more often. This was enhanced by anodal stimulation - confirming the general trend previously reported in literature (see table below).

\begin{tabular}{llll}
\hline & & Mean & $S D$ \\
\hline Cathodal & Postponed & 11.31 & 6.97 \\
\multirow{2}{*}{ Sham } & Immediate & 14.77 & 6.88 \\
& Postponed & 10.23 & 7.53 \\
Anodal & Immediate & 14.00 & 7.33 \\
& Postponed & 12.08 & 7.34 \\
& Immediate & 15.69 & 6.45 \\
\hline
\end{tabular}

Preference for Postponed vs. Immediate reward according to tDSC condition 